\title{
Visualization of integrated indicators of information risk in decision support systems
}

Skvortsova, M., Terekhov, V., Proletarsky, A., Skvortsov, V. and Kochneva, M.

This is a paper presented at the 2020 IEEE Conf. of Russian Young Researchers in Electrical and Electronic Engineering, Moscow, Russia, 27-30 Jan. 2020.

Copyright of the author(s). Reproduced here with their permission and the permission of the conference organisers.

\section{Recommended citation:}

Skvortsova, M., Terekhov, V., Proletarsky, A., Skvortsov, V. and Kochneva, M. (2020) 'Visualization of integrated indicators of information risk in decision support systems.' In: Proc. 2020 IEEE Conf. of Russian Young Researchers in Electrical and Electronic Engineering, Moscow, Russia, 27-30 Jan. 2020, pp. 2101-2105. doi: 10.1109/EIConRus49466.2020.9038952. 


\section{Visualization of Integrated Indicators of Information Risk in Decision Support Systems}

\author{
Maria Skvortsova, Valery Terekhov, \\ Andrey Proletarsky, Vadim Skvortsov \\ Bauman Moscow State Technical University, BMSTU \\ Moscow, Russia \\ magavrilova@bmstu.ru, terekchow@bmstu.ru, \\ pav@bmstu.ru, skvaal@bmstu.ru
}

\author{
Maria Kochneva \\ Faculty of Art, Science and Technology \\ Wrexham Glyndwr University \\ Plas Coch, Mold Road, Wrexham, LL11 2AW, UK
}

\begin{abstract}
Decision-making is one of the essential functions of any manager. The means of visualization play a crucial role in supporting the manager in the decision-making process. This paper discusses the visualisation of information risks based on integral indicators. It provides a description of a mathematical model of the method of dynamic meta-anamorphosis and an example of its practical implementation. The advantages of using a hybrid approach to the development of dynamic metaanamorphosis are discussed.
\end{abstract}

Keywords-information risk; integral indicator; decision support system; risk; visualisation; method of dynamical metaanamorphosis

\section{INTRODUCTION}

Over the last decades, the amount and intensity of information produced and consumed in the world are dramatically increased. The rapid growth of the information streams is linked to the fast transition of the world to the next stage of development where the technical and technological innovations play a crucial role. Hence, it requires a significant amount of knowledge for creating, developing, implementing, and disseminating various innovations [1]-[4]. It is predicted that in the near future the information will be the most valuable product which overall cost could be higher than the total cost of material products. In the future world, the sustainable resourcesaving manufacturing of material products and services will require conceptually new technologies based on the intensive growth of knowledge, efficient search, storage, dissemination, and system integration. This is why information and its associated technologies, including the emerging market of information services are objects of intensive studies across the world.

Inappropriate use, processing, and management of information can bring reputational and financial damages to companies, governments, and economies in general. Information risks affecting confidentiality, integrity, and availability of information have to be taken into account by decision-makers (DM) to provide an optimum and timeliness management decision. The effectiveness and success of the decision significantly depend on the time when the decisive action is implemented. In the area of social-economic activity, too early or too late introduction of quality developed decision can completely neglect its positive effect or even make the post-decision situation worse [3]. The decisions not taken in the required time have no conditions for the successful implementation and development. Moreover, the decisions taken too early may provoke and spur the development of negative trends.

\section{THEORETICAL BACKGROUND AND METHODS}

\section{A. Theoretical Investigation of the Risk Domain}

Analysis of publications related to the risk issues concludes that risk is a complex phenomenon comprising many diverse and sometimes contradicted components. In general, the risk is defined as a set of hazards having the potential of a negative outcome which can bring unpredictable losses [3],[7],[8]. Threat-making risk is the risk where the possibility of a negative outcome is increased proportionally to the negative actions.

Information risk is considered as an event that directly impacts information integrity, confidentiality, and availability [3],[7],[8]. The information risks can be systemised using the criteria represented in Fig. 1.

Fig. 2 shows the universal classification of strategic risks. The classification is based on the legislative documents [3] and expert opinions.

The system applied for the information risk analysis should have a known structure including input and output parameters [7],[8]. For this system, the input variables are the values of five risk factors in the interval $[0,1]$ described using a linguistic term-set (very low, low, average, high, very high) as shown in Table. 1 . Table 2 represents the description of various threats in relation to the risk factors [6],[7].

An editor (DM) can model the risk and threats using a set of defining indicators. The modelling results provide a report of the information risks assessment in a particular area of public life based on the indicator values. The assessment report is the source for the development of the recommendations on the general status of information risks. For example, if the integral indicator has the values "Tense", the DM should decide to introduce preventive preparations. If any indicator equals "Crisis", the decision has to start direct preparations. 


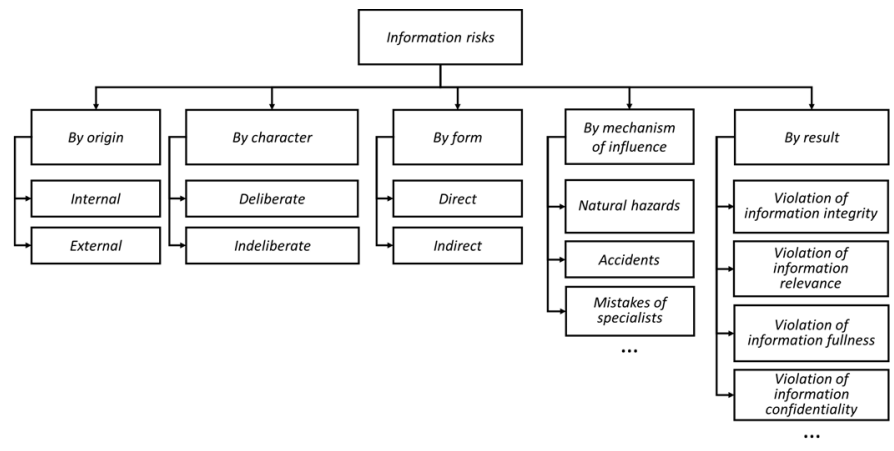

Fig. 1. Classification of information risks.

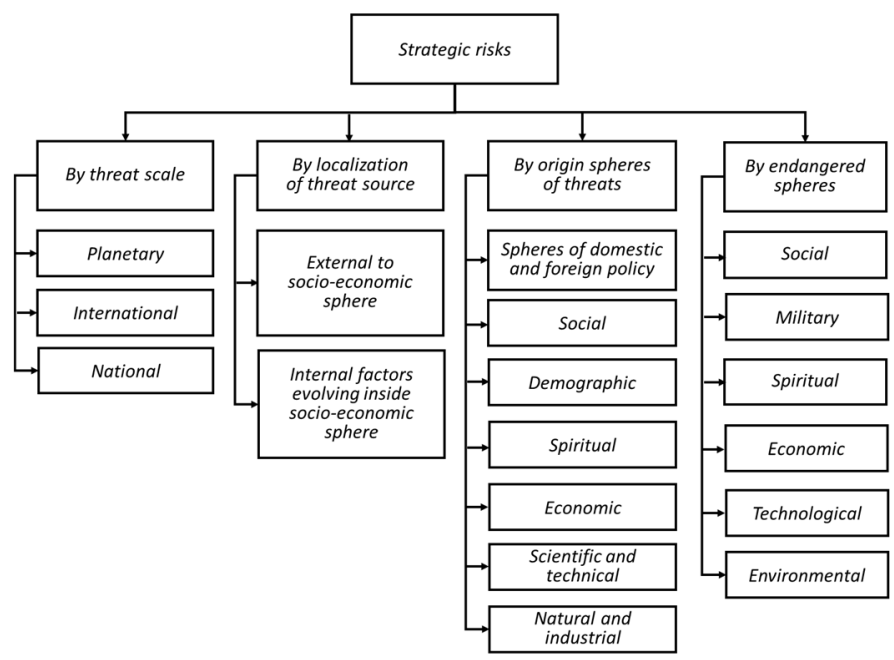

Fig. 2. Universal classification of strategic risks.

TABLE I. SCALE LEVELS FOR RISK FACTORS’ ASSESSMENT

\begin{tabular}{|l|l|l|}
\hline \multicolumn{1}{|c|}{ Scale levels } & \multicolumn{1}{|c|}{ Risk } & \multicolumn{1}{c|}{ Damage } \\
\hline $\begin{array}{l}\text { Very low } \\
\text { from } 0 \text { to 0.2) }\end{array}$ & $\begin{array}{l}\text { The event almost } \\
\text { never happens }\end{array}$ & $\begin{array}{l}\text { Quickly recovered, } \\
\text { insignificant loss of } \\
\text { materials and resources }\end{array}$ \\
\hline $\begin{array}{l}\text { low } \\
\text { (from } 0.2 \text { to 0.4) }\end{array}$ & Rare event & $\begin{array}{l}\text { More significant loss of } \\
\text { material assets, significant } \\
\text { impact on the reputation } \\
\text { and infringement of } \\
\text { interests }\end{array}$ \\
\hline $\begin{array}{l}\text { Average } \\
\text { from } 0.4 \text { to 0.6) }\end{array}$ & $\begin{array}{l}\text { The event is quite } \\
\text { possible under certain } \\
\text { circumstances }\end{array}$ & $\begin{array}{l}\text { Significant loss of material } \\
\text { assets or resources or } \\
\text { significant damage to } \\
\text { reputation and interests }\end{array}$ \\
\hline $\begin{array}{l}\text { High } \\
\text { (from } 0.6 \text { to 0.8) }\end{array}$ & $\begin{array}{l}\text { Most likely, the event } \\
\text { will occur under some } \\
\text { circumstances }\end{array}$ & $\begin{array}{l}\text { Significant damage to } \\
\text { reputation and interests, } \\
\text { poses a serious threat }\end{array}$ \\
\hline $\begin{array}{l}\text { Very high } \\
\text { (from } 0.8 \text { to 1) }\end{array}$ & $\begin{array}{l}\text { The event is most } \\
\text { likely to happen with } \\
\text { a high probability }\end{array}$ & Destructive consequences \\
\hline
\end{tabular}

The state of the integral indicator is determined using analysis of the lower level indicators - the rank 1 and 2 indicators. Rank 1 indicators include indicators to "start direct preparations immediately"; all other indicators are Rank 2 indicators.

The values of the integral indicators are determined as follows. The values of the Rank 1 indicators for "immediate decision to start direct preparation" are determined first. Such an indicator is selected for each type of crisis scenario.

TABLE II. ClassificATION OF THREATS By RISK FACtORS

\begin{tabular}{|l|l|}
\hline \multicolumn{1}{|c|}{ Risk characteristic } & \multicolumn{1}{c|}{ Types of threats } \\
\hline Possibility of forecasting & Predictable, unpredictable \\
\hline Character of emergence & Objective, subjective \\
\hline Form of manifestation & Overt (visible), latent(hidden) \\
\hline Entities subjected to hazard & $\begin{array}{l}\text { Taxation potential, budget incomes, } \\
\text { public and private properties, economic } \\
\text { resources. }\end{array}$ \\
\hline Origin & $\begin{array}{l}\text { Political, economic, legal, criminal, } \\
\text { environmental, competitive, } \\
\text { information, social }\end{array}$ \\
\hline Probability & $\begin{array}{l}\text { Unlikely, likely, very likely, highly } \\
\text { likely }\end{array}$ \\
\hline Scale of damage & Insignificant, significant, catastrophic \\
\hline
\end{tabular}

TABLE III. DECISION MAKING INDICATORS ADVISED TO SWITCH TO PREVENTIVE or DiRECT PREPARATION FOR SWITCHING THE COUNTRY FROM THE PEACE MOdE TO WAR (CRISIS) MODE

\begin{tabular}{|c|c|c|c|c|c|}
\hline \multirow[b]{2}{*}{$\begin{array}{l}\mathrm{N} \\
\mathrm{o}\end{array}$} & \multirow{2}{*}{$\begin{array}{l}\text { Integral } \\
\text { indicator of } \\
\text { the socio- } \\
\text { economic } \\
\text { situation }\end{array}$} & \multicolumn{4}{|c|}{ Indicators of the situation in different areas } \\
\hline & & $\begin{array}{l}\text { Military } \\
\text { and } \\
\text { political }\end{array}$ & Economical & Social & Information \\
\hline 1 & Normal & Normal & Normal & Normal & Normal \\
\hline 2 & $\begin{array}{c}\text { Tense } \\
\text { (preventive } \\
\text { preparation) }\end{array}$ & Tense & $\begin{array}{l}\text { Normal } \\
\text { Tense }\end{array}$ & $\begin{array}{c}\text { Normal } \\
\text { Tense }\end{array}$ & Tense \\
\hline 3 & $\begin{array}{c}\text { Crisis } \\
\text { (immediate } \\
\text { preparation) }\end{array}$ & Crisis & $\begin{array}{l}\text { Normal } \\
\text { Tense } \\
\text { Crisis }\end{array}$ & $\begin{array}{c}\text { Normal } \\
\text { Tense } \\
\text { Crisis }\end{array}$ & $\begin{array}{l}\text { Tense } \\
\text { Crisis }\end{array}$ \\
\hline
\end{tabular}

\section{B. Basis of the Method of Dynamic Meta-anamorphing}

The authors propose to implement the methods of cognitive computer graphics, particularly the method of dynamic metaanamorphing focused on refining and correcting the forecast results for processes in complex decision support systems.

The proposed idea suggests that one (or several most relevant to DM) indicator varying in time and space is assumed to be uniformly distributed while all other indicators are analysed on its background. The analysis utilises the transformation of the original visual image representing a given task from Euclidean space to conventional space. The transformation is defined as the switch from the visual image based on the Euclidean metric to another visual image based on the metric of considered indicator or indicators.

Such transformed visual images are usually called anamorphoses [10]. The image transformed using anamorphing approach generally contains more information compared to the original image. Thus, the original, merely illustrative image is capable of helping DM to produce new ideas and thoughts to make tentative decisions. Therefore, the original, illustrative function of an image is transformed into a cognitive function [10],[11].

This approach can be viewed as a method for merging indicators (analytical, statistical, probabilistic, etc.) and forms of visual images in such a way that the areas of the original visual images are transformed proportional to the selected indicator (anamorphosis) or the integral values of the indicator (meta-anamorphosis). This method allows the DM to refine the 
results of forecasting the processes' development in complex social-technical systems and adjust the decision.

The main principle of the anamorphing method is that the graphical part of the decision (the original visual image) built in the Euclidean space is transformed (anamorphed) on the basis of the selected indicators into a specific two-dimensional graphical image. The internal structure of this graphical image is altered in such a way that the distribution of the selected indicators is uniform while preserving the topological similarity to the original graphical image (Fig. 3).
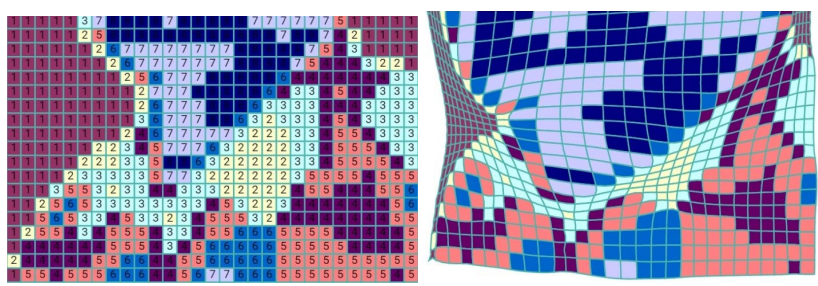

Fig. 3. Part of the original matrix and the generated anamorphosis with the average indicator density $\rho=4.5$.

The method of meta-anamorphing utilises the Line Integral method proposed in [12]. It preserves the topology of the original image, has a low computational complexity of preprocessing the input data, and the adequate speed of convergence. This method is capable of working with many indicators of different physical nature which can be convolved into an integral indicator. The extended functional capability of the method was obtained employing accelerating convergence, construction of special functions preserving the topological connectivity of the image. Other method modifications utilise neural networks at the early steps of the algorithm applicable for some architectures where the computation process subsequently is transferred to CPU to achieve a required transformation accuracy and parallelisation of computations. This approach is the basis for the development of the metaanamorphing method (MAA) [13]. It should be noted that none of the existing programs performing such transformations has the capability of working with integral indicators. Integration of a temporal component in MAA modified it into a hybrid meta-anamorphing method based on MAA and generic programming [9]. In this method, local time-varying indicators are represented as time series, and they are forecasted using symbolic regression. The implementation of symbolic regression implies the generation of a formula represented as a syntax tree using genetic programming methods.

\section{Anamorhing Algorithm}

The anamorphing algorithm can be described as follows. At an infinite plane subdivided into arbitrary areas, there is a limited selected area - cell (the area can be assumed circular without the loss of generality) where the indicator density distribution is different from the average value on the entire plane (at the rest of the plane the density value is average). If the influence of an arbitrary cell on the vertices of the considered cell is determined, then the algorithm considered will converge faster [10].

Any connected areas of arbitrary shape are used as cells. If the distance from the cell centre to a vertex is greater than $\sqrt{s_{i} / \pi}$, where $s_{i}$ is the area of the $i$-th cell, then the influence of the cell on this vertex is inversely proportional to the distance. The length of the vector of translation of the vertex caused by the cell having the distance $r$ from its center is equal to $\left(R_{i}-\bar{R}_{l}\right) \cdot R_{i} / r$, where $R_{i}=\sqrt{s_{i} / \pi}, \overline{R_{l}}=\sqrt{\overline{s_{l}} / \pi}, \overline{s_{l}}$ is the area the cell should have at the anamorphosis according to the density distribution of the considered indicator $\left(\overline{s_{l}}=s_{i} \cdot \rho_{i} / \bar{\rho}\right.$ where $\rho_{i}$-indicator density in the cell $i, \bar{\rho}$-average indicator density for the whole territory). If the distance from the center of the cell to the vertex is less than $\sqrt{s_{i} / \pi}$, then the distance relationship is chosen so that it would be differentiable for all $r>0$.

The study published in [9] demonstrated the development of an algorithm efficiently constructing anamorphoses in realtime. This algorithm is invariant, i.e., its result is independent of the implementation specifics. For example, if there are $N$ cells as areas of arbitrary form, where the boundary of each area is described with vertices, then the influence of any cell on the considered vertex can be defined based on the following considerations. Let an arbitrary cell have the area: $s_{i}=0,5$. $\left[\left(x_{i 1}-x_{i 2}\right)\left(y_{i 1}+y_{i 2}\right)+\cdots+\left(x_{i(n-1)}-x_{i n}\right)\left(y_{i(n-1)}+\right.\right.$ $\left.\left.y_{i n}\right)\right], \rho_{i}(x, y)=\rho_{i}$. In the case of anamorphing, it must be transformed in such a way that its area is equal to $\overline{s_{l}}$. If the area of the cell is set equal to the area of the circle with the radius $R=\sqrt{s_{i} / \pi}$, then the anamorphing transforms this circle into a circle with the radius $\bar{R}=\sqrt{\overline{s_{l}} / \pi}$ via homothetic transformation, and the indicator value for the other planar figure is preserved. In the polar coordinate system with the origin in the circle centre, anamorphing is done when the vertex $(r, \varphi)$ is transformed into the vertex $(\bar{r}, \bar{\varphi})$.

$$
\left\{\begin{array}{c}
(\bar{R} / R) \cdot r \text { if } r \leq R \\
\sqrt{r^{2}+\left(\bar{R}^{2}-R^{2}\right)} \text { if } r>R
\end{array},\right.
$$

where $\varphi=\bar{\varphi}, r$ is the distance between the considered cell vertex and the centre of the cell influencing the vertex.

The influence of the centre of a cell on any other vertex of another cell is represented by translating this vertex by the distance of $r \cdot(\bar{R} / R-1)$ if $r \leq R$ and $\sqrt{r^{2}+\left(\bar{R}^{2}-R^{2}\right)}-r$ if $r>R$. This influence is described by the radius-vector of the polygon vertex $\bar{v}$ with the origin in the cell center multiplied by the coefficient $(\bar{R} / R-1)$ if $r \leq R$ or $\sqrt{1+\left(\bar{R}^{2}-R^{2}\right) / r^{2}}-1$ if $r>R$. At the cell center, any point inside the cell can be chosen, for example, a geometrical centre or the centre of gravity of the cell. For map-making purposes, capitals and centres of the territories being anamorphed can be used as cell centres.

The method intensively uses iterative procedures because the transformation yielding the required anamorphosis can not be executed in one step. At every step, the procedures calculate the density deviation relative to $\bar{\rho}$ for the whole planar figure and change it accordingly. The iterative process stops when all relative deviations of the cell areas are less than a set value $\varepsilon$, and the indicators in all cells are equal to $\bar{\rho}$ (Fig. 4 ). 


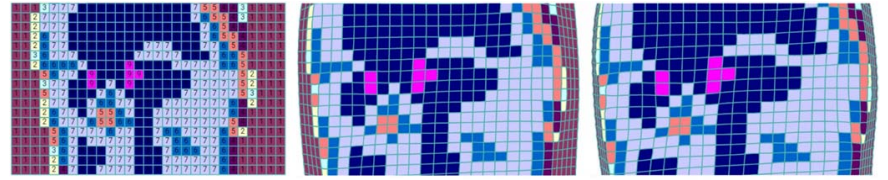

Fig. 4. Subsequent steps of transforming the original matrix. The figure shows the original matrix, the intermediate anamorphosis at the 5 th step, and the final anamorphosis at the 25th step for $\bar{\rho}=4,5$ and $\varepsilon=0,01$.

A meta-anamorphosis can also be developed using the approach that any physical indicators are recalculated as areas of circles illuminating the units of the indicators and normalise it for any scale convenient for calculations. Therefore, the authors can propose the calculation of the integral anamorphing indicator to get the integral matrix of the anamorphing indicators representing a convolution of $K$ local indicators relevant to the given problem. Fig. 5 shows the example of calculating a meta-anamorphosis based on an integral indicator, which is an additive convolution of three local indicators.

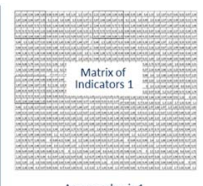

Anamorphosis
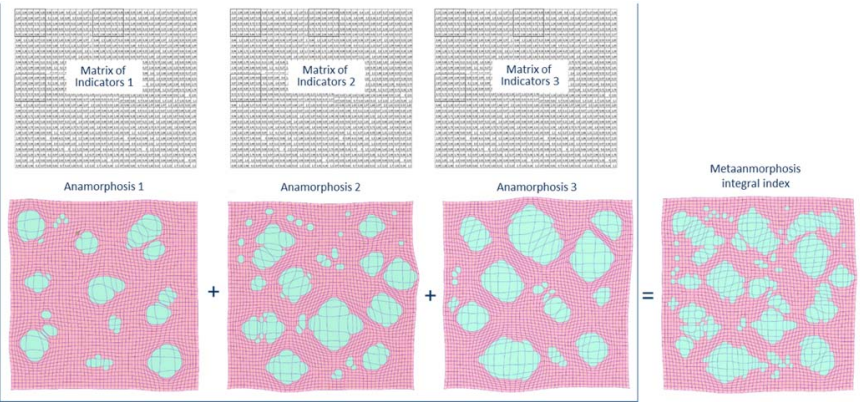

Fig. 5. Meta-anamorphosis built using a convolution of three local indicators.

The study discussed in [9] leads to the development of a hybrid method of dynamic meta-anamorphosis. In that algorithm, problem-relevant local indicators varying in time can be considered as time series and can be forecasted using symbolic regression which is one of the methods of artificial intelligence.

Symbolic regression is a method of constructing regression models by searching different arbitrary superpositions of function from a specific set. The implementation of symbolic regression means generating a formula represented as a syntax tree using genetic programming methods (a particular case of genetic algorithms working with syntax trees of arbitrary length).

The task of forecasting a time series of local indicators is solved by providing to the genetic algorithm a set of values of the original time series of local indicators and a set of basis functions for constructing a syntax tree. The genetic algorithm is then used to form a syntax tree which is the analytical description of the function. The fitness function of the algorithm is the error of approximation of the original time series of local indicators and the series generated by the syntax tree, and the genetic algorithm tries to minimise this error and achieve the maximum accuracy approximation accuracy [14$15]$.

The advantage of the proposed approach is the possibility to correct the syntax tree during operation. If the new data sets come in, the genetic algorithm performs additional steps and thus modifies the analytical form of the function (syntax tree) so that the function can now approximate both the old and the new data.

If values of local indicators with different physical origin are calculated for each time point $t(t=1 \div T)$, it can be convoluted in an integral anamorphing indicator $K_{t}$ and construct the anamorphosis $A_{t}$ based on it (Fig. 6).

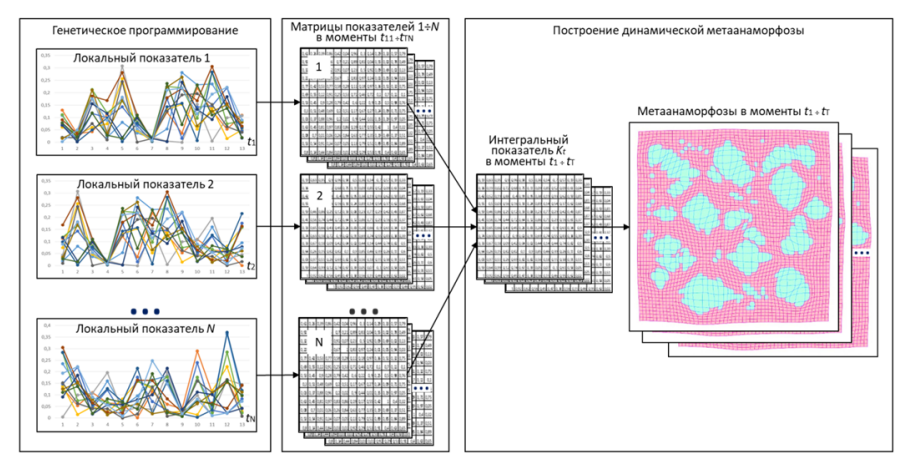

Fig. 6. Dynamic meta-anamorphosis based on the forecasted values of local indicators $1 \div \mathrm{N}$ at time points $\mathrm{t}_{1} \div \mathrm{t}_{\mathrm{N}}$.

\section{PRACTICAL IMPLEMENTATION}

To demonstrate practical implementation of the proposed method, the authors analysed the open-access data [16],[17] of the population density for various areas of the city of Moscow. The areas where the population density is higher than 15,000 people per $\mathrm{km}^{2}$ show a risk of increased crime rate, illegal immigration, and other types of illegal activity.

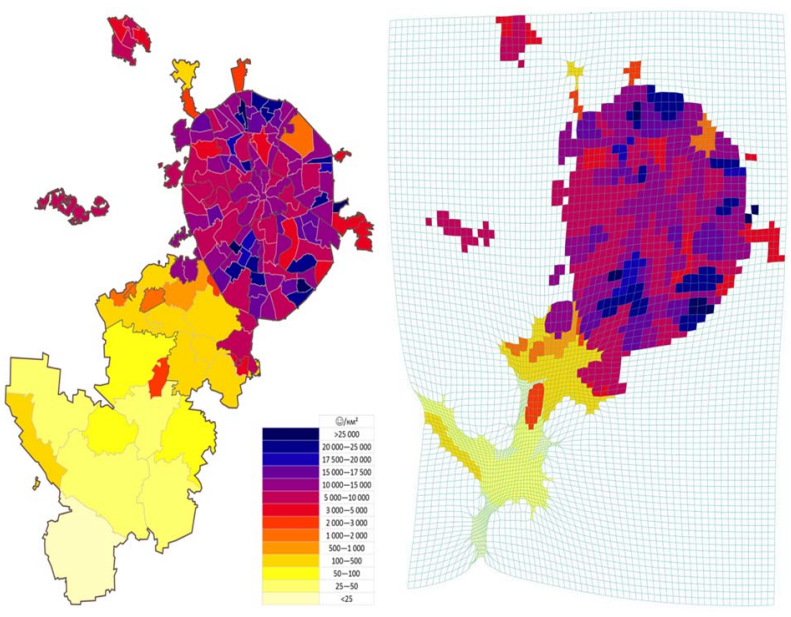

Fig. 7. Anamorphosis of the population density for different areas of the city of Moscow.

\section{DISCUSSION}

The issue of convolving indicators for the given subject domain is a complex task requiring further research. At present, it is solved using the expert approach. The hybrid approach allows constructing a dynamic meta-anamorphosis based on forecasted values of local indicators and have the following evident advantages for refining and correcting the obtained results of forecasting integral indicators of information risk: 
- It provides reducing the dimensionality of the problem by the number of local indicators of different physical origin convolved in the integral information risk indicator;

- It provides a possibility of visual modelling and decisionmaking, taking into account the time-varying local/integral indicators of different physical origins. This allows identifying negative/positive tendencies in the change of given indicators of the process analysed and propose qualitative and quantitative measures to eliminate them or reducing the information risk to the preset values;

- It identifies hidden laws of change of different parameters of the given problem in time which are implicitly related to the integral information risk indicator;

- It provides constructing the scenarios of DM actions based on visual spatial-temporal analysis of dynamical metaanamorphosis, taking into account the processes related to the speed of the evolution of the integral information risk indicator.

\section{CONCLUSION}

This paper proposed a solution to the task of visualising integral information risk using the dynamic meta-anamorphosis method. The authors considered the usage specifics of cognitive graphics methods including, in particular, the method of dynamic meta-anamorphing for visual modelling of results of forecasting the development of various processes in decision support systems.

This spatial-temporal modelling is avalable in the space of uniform distribution of integral risk indicators and allows refining and correcting the obtained results of forecasting in decision support systems and making informed decisions.

The obtained theoretical results and the presented examples confirm the possibility of using dynamic meta-anamorphosis for visualising the developed algorithms, as well as for analysis and forecasting of development of conflict situations in decision support systems.

\section{REFERENCES}

[1] K. Schwab, The Fourth Industrial Revolution. New York: Crown Publishing Group, 2016.

[2] M.E.J. Newman, "The structure and function of complex networks," SIAM Review, vol. 45, no.2, pp. 167-256, 2003.

[3] Official website of Kremlin (2019). Available at: http://kremlin.ru/ (Accessed 28 November 2019)

[4] J.F. Allen, and G. Ferguson, "Actions and events in interval temporal logic," Journal of Logic and Computation, vol. 4, no. 5, pp. 531-579, 1994.

[5] T.L. Saaty, The Analytic Hierarchy Process. New York: McGraw-Hill, 1980.

[6] V. Chernenkiy, Y. Gapanyuk, V. Terekhov, G. Revunkov, and Y. Kaganov, "The hybrid intelligent information system approach as the basis for cognitive architecture," Procedia Computer Science, vol. 145, pp. 143-152, 2018.

[7] M. Skvortsova, V. Terekhov, and V. Grout, "Hybrid intelligent system for risk assessment based on unstructured data," in Proc. 2017 IEEE Conf. of Russian Young Researchers in Electrical and Electronic Engineering, 1-3 Feb. 2017, St. Petersburg, Russia, pp. 560-564.

[8] M. Skvortsova, and V. Terekhov, "Study of the possibility of applying intellectual methods in creating risk analysis decision support system in the socio-economic sphere," in Proc. 2019 IEEE Conf. of Russian Young Researchers in Electrical and Electronic Engineering, 28-31 Jan. 2019, Moscow, Russia, pp. 1892-1896.

[9] Terekhov V., Chernenky I., Buklin S., Yakubov A. Cognitive Visualization in Management Decision Support Problems. Optical Memory and Neural Networks, 2019, Vol. 28, No. 1, pp. 27-35.

[10] S.M. Gusein-Zade, and V.S. Tikunov, Anamorphoses: What Are They? Moscow: Editorial URSS, 1999.

[11] A.A. Zenkin, Cognitive Computer Graphics. Nauka, 1991.

[12] S.M. Gusein-Zade, and V.S. Tikunov, "A new technique for constructing continuous cartograms," Cartography and Geographic Information Systems, vol. 20, no. 3, pp. 167-173, 1993.

[13] A.V. Proletarsky, D.V. Berezkin, Y.E. Gapanyuk, I.A. Kozlov, I.A. Popov, R.S. Samarev, and V.I. Terekhov, "Methods of situation analysis and graphical visualization of big data streams," Herald of the Bauman Moscow State Technical University - Series Instrument Engineering, vol. 119, no. 2, pp. 98-123, 2018. (in Russian)

[14] J. Koza, Genetic Programming: On the Programming of Computers by Means of Natural Selection. Boston, MA: MIT Press, 1992.

[15] V. Chernenkiy, Y. Gapanyuk, G. Revunkov, Y. Kaganov, and Y. Fedorenko, "Metagraph approach as a data model for cognitive architecture," in Biologically Inspired Cognitive Architectures 2018, vol. 848, Advances in Intelligent Systems and Computing, A.V. Samsonovich, Ed., Cham, Switzerland: Springer, 2019, pp. 50-55.

[16] Portal of open data. Available at https://data.gov.ru/ (Accessed 28 November 2019)

[17] Portal of open data of the government of Moscow. Available at https://data.mos.ru/ (Accessed 28 November 2019) 